\title{
Arbor
}

\section{Cohesión e ideal sociales en la España de los Reyes Católicos ${ }^{1}$}

\section{Luis Suárez}

Arbor CLXXVIII, 701 (Mayo 2004), 1-30 pp.

Para comprender qué fue la Monarquía de los Reyes Católicos -Monarquía Católica española, como la denominaría Tommasso Campanella un siglo más tarde- tenemos que desprendernos de muchas opiniones de nuestros días e intentar referirnos a los valores, ideas y opiniones que conformaban la sociedad europea de aquel tiempo. En el tránsito de la Edad Media a la Modernidad no existía ningún valor comparable al de la fe, fundamento de toda sociedad a la que definía, haciéndola cristiana, judía o musulmana. Un judío o musulmán que se convertía dejaba automáticamente de pertenecer a su sociedad pasando a integrarse en la cristiana. De este modo el naciente Estado se atribuía, como primera y primordial misión, la de proporcionar medios necesarios para llevar esa fe hasta sus últimas consecuencias. Femando e Isabel se colocaron en la misma dirección en que iba a situarse Martin Lutero con su cuius regio eius religio, aunque con una diferencia de sentido, cuius religio eius regio. Era la Monarquía la que debía plegarse a los imperativos de la fe y no al contrario.

Si se acepta que el hombre es un ser transitorio, no hacia la muerte sino hacia la eternidad -«que se acuerde que hemos de morir» es el último consejo de Isabel a su marido- y en ella se produce el encuentro definitivo con Dios, ningún bien puede ser comparable al de la fe, verdad absoluta, certeza que procede del mismo Dios que la ha revelado, seguridad descansada, criterio de razón y norma de moral mediante la cual el hombre puede alcanzar la plena dignidad. Tal era el criterio de fines del siglo $\mathrm{XV}$, no el nuestro. Proporcionar a sus súbditos el acceso a la fe si aun no la tienen, conservarlos en ella, hacerlas crecer, ese era el bien por excelencia. 
Por otra parte, la Monarquía, al consolidarse como una forma de Estado, la más persistente de las conocidas en España, estaba practicando una especie de identificación entre la sociedad, comunidad política, y el rey, depositario de la soberanía. Este rey no debe su oficio a elección o delegación del reino sino a una designación divina, por el camino objetivo de la herencia, mediante la cual se le impone el deber, y no el derecho, de reinar. De este deber es del que, en la hora suprema de la muerte, como dirá insistentemente Isabel, tendrá que rendir cuentas a Dios que no a los hombres. Una comunidad política perfecta es aquella que alcanza la unidad de fe eliminando del solar que ella ocupa a las otras confesiones que puedan perturbarla: no se trataba de eliminar a hombres sino a creencias.

A esta línea de conducta es a la que los historiadores actuales pretendemos llamar «máximo religioso» para establecer una contraposición con el «mínimo» que Jean Bodin proclamaría en Francia en los años finales del siglo XVI. Una y otra doctrina tienen importantes consecuencias, en especial, en el caso del máximo, porque todas las leyes quedaban sometidas al orden moral defendido por la Iglesia lo que, en una época inclinada cada vez con mayor vigor al absolutismo, sirvió evidentemente de freno. El Estado naciente se relativizaba al convertirse en poder subsidiario cuyo contenido primero e indeclinable consistía en lograr que el bien absoluto de la fe penetrara y articulara la vida entera. Se insiste mucho ahora en destacar el efecto negativo de la intolerancia, que fue verdadera, pero no en cambio el positivo. La Monarquía no tenía más remedio que reconocer, como harían maestros de la llamada escuela de Salamanca, la existencia de unos derechos, que eran «naturales» porque habían sido insertos por el propio Dios en la naturaleza de sus criaturas. No era posible acudir a la «razón de Estado». De ahí que, pese a la Inquisición, hubiese en ella mayores dosis de libertad que en otras partes.

Desde 1492 la Corona española domina ampliamente la Península. Existe todavía Navarra como reino, englobando en un conjunto de dominios feudales franceses, de la Casa Albret y Foix, que no tardará en ser «rescatado» para la españolidad, y también Portugal, con quien las relaciones se han tornado muy singulares en los últimos tiempos ya que una misma familia, conformada por insistentes enlaces, gobierna en ambos reinos. Lo que parece última piedra del edificio, Granada, se ha colocado precisamente al comenzar ese año. Los cronistas afirman que se ha producido la «restauración» de España; y eso mismo habían explicado tres o cuatro años antes los embajadores de Fernando al Sultán de Babilonia, 


\section{Cohesión e ideal sociales en la España de los RR.CC.}

en Egipto, esto es, que no se trataba sino de recobrar algo que de derecho le pertenecía.

La restauración se refería no a una cuestión política sino religiosa: la España cristiana existente en el siglo VIII había sido destruida por el Islam que, poco a poco, logró desarraigar la fe trinitaria del suelo andalusí. Por eso la celebración de la primera misa en la Alhambra, al amanecer del 2 de enero de 1492, inmediatamente después de que Gutierre de Cárdenas recibiese las llaves de manos de Boabdil, está llena de significado. Sobreviven en adelante diferentes estructuras políticas e institucionales, pero no, en cambio, religiosas.

Este es el rasgo primero que conforma la mentalidad social, en las postrimerías del siglo XV: la condición se súbdito de los Reyes o, como diríamos en términos actuales, de ciudadano, su «naturaleza» pertenece únicamente a los bautizados. Los infieles, es decir, no bautizados -salvo aquellos que han llegado en calidad de esclavos y por consiguiente carecen de todo derecho-, acomodan su presencia a ciertas concesiones y pactos otorgados por el Rey. Pactos que son revisables pues se trata de concesiones: en 1492 se hará la primera de dichas revisiones ordenando la salida de los judíos que no quieran bautizarse; en 1500 se hará lo mismo con los musulmanes salvo en Valencia donde permanecerán todavía un siglo.

De hecho, esta mentalidad restrictiva, que reserva los derechos políticos únicamente a los que profesan la religión común, estaba siendo presentada como signo de modernidad. Todas las Monarquías europeas, conforme alcanzaban la madurez institucional pertinente, adoptaban el mismo criterio: los judíos habían sido excluidos de Inglaterra a finales del siglo XIII, de Francia y Nápoles al principio del siglo XIV y casi al mismo tiempo de los principados italianos. De modo que la tolerancia hacia los "infieles» no era contemplada como progreso sino como signo de atraso. Así lo manifiesta la Universidad de París en su carta a los Reyes.

Esta identificación entre estructura política y doctrina religiosa tenía otras consecuencias: el poder real y el de las leyes se encontraban sometidos a fuertes limitaciones ya que existía un ámbito de la persona humana al que aquellos no podían llegar; el Estado naciente no atribuía al Príncipe la custodia de la moral porque ésta corresponde a la Iglesia. La única posibilidad que se ofrecía al monarca, dentro de esta mentalidad, no era otra sino la que Enrique VIII en Inglaterra decidió utilizar: excluir al Papa convirtiéndose él mismo en cabeza de la Iglesia. Es el principio de modernidad al que aludía Lutero cuando afirmó cuius regio eius reli- 
gio, esto es, el derecho del Príncipe a imponer a sus súbditos la norma moral. En España esto no sucedió. Calderón lo explicaba a sus espectadores: «al rey la hacienda y la vida se deben dar, pero el honor es patrimonio del alma, y el alma sólo es de Dios».

Esta mentalidad tenía dos aspectos muy diferentes, a menudo contradictorios, que explican que hayan podido producirse alabanzas y vituperios, al no tener en cuenta más que uno de ellos. Por una parte, confundía transigencia y tolerancia, como si de un mismo concepto se tratase. Aún hoy en el lenguaje corriente los españoles suelen identificarlos, incurriendo en error. Pues no transigir significa que uno no está dispuesto a abdicar de creencias o certezas que le parecen fuera de duda: para un cristiano la divinidad de Jesucristo no es opinión que pueda dar origen a transacciones; en este aspecto es absolutamente intransigente. Mientras que tolerar significa respetar las opiniones y doctrinas que otros sostienen, aunque se sepa que son erróneas o malas. Pero si las mezclamos, la adhesión a la verdad impulsa a perseguir a quienes no la comparten o, al contrario - como hoy sucede- aceptar a esos que disienten significa abandonar sus propias convicciones. Convengamos en que esto no es bueno.

Por otra parte, este español tornado hacia la intolerancia precisamente por haber adquirido un esquema de valores indudables, poseía una ventaja sobre los súbditos de otros países. Siendo la Iglesia custodia -y sólo custodia- de una moral que forma parte del designio de Dios sobre la Creación, dicha moral era reconocida como inserta en la naturaleza humana: bien y mal, justo o injusto, no responden a criterios variables de utilidad o provecho sino que forman parte de una «ley natural» que se halla inserta en el alma de cada ser humano. De aquí los juristas y teólogos españoles, en un trabajo que abarca dos o tres generaciones, extrajeron la doctrina del derecho de gentes y el reconocimiento de que todos los seres humanos y, en primer término, los habitantes de las «islas e Tierra Firme recién des cubiertas» están asistidos de ese derecho esencial que a nadie excluye.

\section{La importancia de Isabel}

Como una consecuencia lógica de este planteamiento nos encontramos con un aspecto de la política de los Reyes Católicos que podemos definir como favorecedora de las corrientes creadoras de santidad, ya que de ella dependían la unidad y vitalidad de la fe. Una abundante docu- 
mentación confirma el argumento de que Isabel siguió conscientemente un programa de estímulo a cuantas instituciones sirviesen para fomentarla. Comenzando por ella misma que fue contagiada desde sus primeros años por quienes la rodeaban, aconsejaban o educaban. Cuando las Cortes de Europa conocían un verdadero vendaval de sensualidad, Isabel impuso en ella la modestia, la honestidad, la vida religiosa, de tal modo que, según el testimonio irrebatible de fray Hernando de Talavera, era aquella Corte un verdadero paradigma. Amparó a los bastardos de su marido y a los del cardenal «para que no se le perdiesen» pero frenó a ambos hasta un punto difícil de comprender.

No se trataba de una religiosidad gazmoña, sino abierta al mundo. Hurgando en su biblioteca descubrimos que falta Eiximenis. Desde luego a Isabel complacían los libros del «buen decir de mujeres» y no los que las denostaban. Piedad serena y firme, recogida en la honda presencia de la muerte. En aquella noche terrible de 1492 cuando Fernando estuvo a punto de morir por la cuchillada de un payés loco, ella, que la pasó rezando, confesaba después su angustia porque temía que el rey no se hallara en buena disposición para presentarse ante Dios «en especial en la paga de las deudas».

De ahí también algunas esenciales derivaciones en la conducta: la justicia ejercida con mano rigurosa, el convencimiento de que el deber se antepone a la reclamación de derechos, el sentido de la propia dignidad -Isabel cubría el rostro con un velo para disimular dolores del parto-, el ahorro, la limosna, el afecto comprensivo hacia las personas allegadas. Uno de sus grandes maestros en las tediosas jornadas de Arévalo cuando, una niña, jugaba bajo la mirada atenta de Santa Beatriz de Silva, fue Gómez Manrique. Años más tarde, estando este último en Valladolid en servicio de los reyes, enfermó en la Corte su esposa Juana, Isabel le escribió: «Gómez Manrique, en todo caso venid luego, que doña Juana ha estado muy mal, y estaba mejor, y ha tornado a recaer cuando le dijeron que no veníais». Es todo un rasgo de carácter.

\section{Humanismo y Reforma}

La reforma española, aspecto positivo del «máximo» religioso, se inserta en el vasto movimiento que, entre Petrarca y Tomás Moro, se empeña en dar respuesta al nominalismo que desencadenara Guillermo de Ockham a principios del siglo X. Para los voluntaristas la doctrina de que la iglesia es Cuerpo Místico de Cristo se iba vaciando de sentido, 
pues no puede darse una comunicación real -a lo sumo virtual- entre Dios, que es Trascendencia absoluta, y las criaturas; la Iglesia es, pues, una sociedad humana. Por la misma causa la razón humana está desprovista de medios para lograr un conocimiento de lo trascendente, ya que el hombre es capaz de conocer por medio de los sentidos. Frente a esto, los humanistas defendieron la plena Humanidad de Dios encarnado, esto es, Cristo, la excelsitud de la Virgen María, la capacidad racional para el conocimiento especulativo y la libertad, libre albedrío, como una parte de la naturaleza humana. Los ockhamistas lograron en Constanza una victoria cuando se rechazó la doctrina de la Inmaculada Concepción. Durante siglos el catolicismo español hará de ella una bandera de combate exigiendo un juramento de defenderla a sus maestros universitarios. Así pues, no es una casualidad que el primer libro impreso en España sea, precisamente el de Les trobes en lahors de la Verge María.

El franciscanismo observante en España se presenta a sí mismo como «concepcionista». Las querellas en torno a María y a su papel en la redención, no eran un mero divertimiento de frailes. Europa desembocaba en la Modernidad mientras se producía en ella un fenómeno de ruptura en torno a dos doctrinas acerca del hombre: aquella que afirmaba para él las dos dimensiones de racionalidad y libertad (humanismo) y aquella otra que las negaba encerrándolo en una inmanencia (voluntarismo). Desde la época de los Reyes Católicos, España se convirtió en defensora de la primera y lo haría durante dos siglos con tremendo denuedo. Hacia ese humanismo iba a decantarse la reforma que había comenzado en las últimas décadas del siglo XIV y alcanzaría con Cisneros su primera etapa de madurez.

La reforma religiosa era un fenómeno sumamente complejo. Abarcaba el retorno a la «observancia» de las antiguas reglas monásticas, el arreglo de las deterioradas estructuras económicas de las casas religiosas, restablecimiento de la disciplina en el clero y, sobre todo, elevación del grado de formación que se debía alcanzar con los estudios. Por encima de todo, los reformadores expresaban un sentimiento: vivir con plenitud el cristianismo. Reformadores y humanistas coincidían en que el hombre debía ser educado para que en él aflorasen las «virtudes» esto es, las potencialidades que existen en el alma humana y que son susceptibles de desarrollo. Las virtudes meramente humanas reciben un premio, la «opinión» mientras se vive y la «fama» que perdura después de muertos. Las virtudes sobrenaturales garantizan la vida eterna. 
Cohesión e ideal sociales en la España de los RR.CC.

Constituye un error presentar la reforma tan solo como correctora de graves defectos que habían llegado a penetrar en la Iglesia. Había mucho de esto, pero se trataba sobre todo de dar un paso adelante en esa «Imitación de Cristo» que era uno de los libros de cabecera de la reina. El ideal estaba puesto no en el pasado - «no se engañe nadie pensando que ha de durar lo que espera» dice Jorge Manrique- sino en el futuro. A fin de cuentas -sigamos con Manrique- «este mundo bueno fue si bien usásemos de él como debemos, porque, según nuestra fe, es para ganar aquel que atendemos». En 1453, a punto de morir, el padre de Isabel, Juan II, confesó a sus íntimos que más le valiera «ser hijo de labrador y fraile del Abrojo, que no rey de Castilla».

\section{El origen de la Inquisición}

No encontramos ninguna diferencia en la conducta seguida por Fernando en estos asuntos; la política no experimentó variación alguna tras la muerte de Isabel y en un importante Informe del Consejo de Inquisición de 1507, hay una afirmación todavía más rigurosa si cabe, en su aspecto: los reinos que formaban la Corona tenían que ser purificados por cualquier amenaza, directa o indirecta contra la fe. $\mathrm{Al}$ convertirse en rey de Castilla, Fernando amplió considerablemente el ámbito de poder de la Corona de Aragón: según escritores áulicos que insisten mucho en el tema, la Corona era ya conocida como «señoría mayor» en todo el ámbito peninsular y mediterráneo; por eso empieza a aparecer en los documentos el término Majestad, que excede en mucho al de Alteza hasta entonces de uso corriente. Para expresarlo en términos más próximos a nosotros, esa Majestad soberana significaba una autoridad que sólo a Dios, de quien depende, reconoce como superior.

En consecuencia, los reinos, aunque conservaban su trama institucional, eran considerados como miembros de una comunidad política incardinada en la única Corona y definida, como dijimos, por la fe católica. Sólo los bautizados eran reconocidos como parte de ella. Podían entrar algunos nacidos fuera si gozaban de dicha condición. En cambio, judíos y musulmanes, aunque descendiesen de varias generaciones de habitantes del territorio, no formaban parte de la comunidad política y su inhabitación en el Reino era consecuencia de una autorización directa del monarca y, como tal, revocable. De acuerdo con la doctrina del «máximo» las tres condiciones de natural, bautizado y súbdito son indispensables para formar parte del Reino. 
No era ésta una singularidad española pues tal era la norma general; lo singular habría sido que se hubiera dejado de exigir esa condición. Ningún cristiano podía formar parte de la comunidad política en países musulmanes; ninguna iglesia cristiana se alzaba en el reino de Granada; las comunidades cristianas de Oriente Próximo gozaban -o padecían- la misma provisional protección. Por eso el decreto de 31 de marzo de 1492 tuvo la forma simple de prohibir a los judíos la estancia en el territorio. No se mencionaba en él a los que quisieran bautizarse, pues esto se daba por sobreentendido: los que se bautizaban al pasar a integrarse en la comunidad no tenían que salir. Y los que, habiendo salido, se convertían, recobraban incluso la condición económica. Hemos podido establecer hasta ahora una lista de 177 nombres que retornaron.

Esa doctrina, que establece como primera de las obligaciones del soberano ayudar a los súbditos a conseguir la vida eterna, no fue enteramente nueva: la encontramos en la documentación medieval, en las Partidas, en el Ordenamiento de Casa y Corte de Pedro IV y en las Cortes de Guadalajara de 1390. Nueva fue, en cambio, la forma en que tal doctrina fue llevada a la práctica. En todos los reinos de Europa la intolerancia religiosa aparece como asociada a la maduración de las formas de Estado. Esa intolerancia no necesitaba ser impuesta desde arriba pues gozaba de popularidad. A los reyes tocaba muchas veces frenar los impulsos de los súbditos. Las Comunidades de Castilla incluyeron la defensa de la Inquisición entre las libertades que reclamaban.

El establecimiento de la Inquisición fue, en no pequeña parte, un repliegue del poder monárquico ante las exigencias del Derecho canónico. Fernando no intentó, como harían los monarcas de Francia o de Inglaterra en el siglo XVI, atribuirse directamente la represión de delitos religiosos, sino que aceptó las Constituciones de Gregorio IX que, desde 1231, reservaban el juicio sobre delitos de «herética pravedad» a un procedimiento especial seguido por jueces especialmente nombrados, que debían ser teólogos expertos, dominicos con posesión del título de maestros. Sólo después de que estos tribunales declarasen probado el delito podía la potestad regia poner el castigo. La Iglesia había establecido esta norma como una precaución frente a posibles abusos de los poderes laicos. Como San Raimundo de Penyafort había dictado normas, que eliminaban aspectos más crueles de la tortura como prueba y los confusos procedimientos de las denuncias indiscriminadas, resultaba que el procedimiento inquisitorial, frente a lo que muchas veces se dice, resultaba menos duro para sus víctimas que el ordinario. 
Cohesión e ideal sociales en la España de los RR.CC.

Los Reyes Católicos no «inventaron» la Inquisición puesto que ya existía aunque en Castilla no se hubiera implantado todavía. De esto se habló en el otoño de 1477 con el nuncio Nicolás Franco en las entrevistas que hemos estudiado de Sevilla. Fernando e Isabel, con su preocupación por la eficacia, trataron de vincular directamente a los jueces inquisidores a su potestad mayestática e independizarlos de la jurisdicción diocesana. En esta línea les empujaban algunos influyentes eclesiásticos de su corte como por ejemplo fray Alonso de Espina, autor del Fortalitium Fi$d e i$, que veía en los conversos una permanente y gravísima amenaza contra la fe católica. El 1 de noviembre de 1478 la bula Exigit sincerae devotionis entregada en Roma al Obispo de Osma y a su hermano, Francisco de Santillán, concedía a los monarcas españoles plenos poderes para escoger los tres inquisidores, personas mayores de cuarenta años, sacerdotes recomendables por su virtud, maestros y bachilleres en Teología, que superasen un examen previo. Tal vez no se advirtiera en el primer momento la gravedad de la concesión: los monarcas españoles iban a tener derecho a proponer nombramiento directo de inquisidores con independencia del General y de los Provinciales dominicos. Caía por tierra una de las precauciones que en el siglo XIII se tomaran.

\section{Torquemada retoma las riendas}

La bula del 1 de noviembre de 1478 no tuvo inmediata aplicación. Parecía además referirse a un punto concreto, Sevilla y su entorno. Hubo un plazo de casi dos años en que se ejercieron presiones muy diversas sobre conversos para moverles al arrepentimiento, penitencia y perdón. Es posible que se haya producido en la misma Corte enfrentamiento entre tendencias opuestas. Pero ya en el año 1480 se tomaron dos disposiciones paralelas: aquella que disponía el radical apartamiento de los barrios judíos para impedir el contacto de los cristianos con quienes podían desviarles de su fe, y el nombramiento de dos inquisidores para Sevilla (27 de septiembre), los padres dominicos fray Miguel de Morillo y fray Juan de San Martín, que tendrían como asesores al capellán López del Barco y al consejero Juan Ruiz de Medina. Sin que la bula les obligase, los reyes habían tomado la precaución de buscar dominicos. Morillo había sido elegido en julio de 1479 Provincial de Aragón.

Isabel se hizo directamente responsable: las cartas que ordenaban al municipio sevillano ponerse a las órdenes de los inquisidores, estaban redactadas exclusivamente a su nombre. Salvo en el nombramiento, no pa- 
recía apreciarse novedad. El procedimiento inquisitorial no variaba: la tortura tendría que aplicarse en todo caso ante la presencia de un médico que la suspendía si veía peligro para la vida o mutilación del reo, y éste era declarado inocente si bajo ella no confesaba. Esto significó que, a pesar de lo mucho que se ha fantaseado, la tortura no era prueba favorita de los inquisidores. Ahora bien, el tribunal procedió con rigor tan extremado que pronto levantó protestas. Las investigaciones del P. Fidel Fita y del P. Bernardino Llorca no permiten dudar. Hubo muchas ejecuciones, penas gravísimas, confiscaciones de bienes.

Desde Sevilla, foco inicial de actuación, se produjo una fuga de conversos. No faltaba entre ellos la gente adinerada y poderosa, capaz de llegar con sus quejas y denuncias al solio pontificio. Es preciso tener en cuenta que en la atmósfera de terror que llegó a apoderarse de Sevilla, existían tensiones contrapuestas: miedo de los conversos ante excesos de la Inquisición, pero miedo también en la sociedad cristiana ante hechos que a los judaizantes se atribuían. En los reyes y quienes les rodeaban nació la voluntad de extenderla a toda la Península, incluyendo la Corona de Aragón -donde funcionaba, en la suave lenidad característica, una vieja Inquisición- en donde la legislación era diferente. Aunque los términos de la bula eran suficientemente amplios - «de los reinos españoles dependientes de vuestra autoridad»-como la fecha era anterior a la muerte de Juan II, era difícil sostener que también se refería a esta parte de la herencia.

Fernando e Isabel intentaron una maniobra en 1481. Convencer al general de los dominicos, Salvio Casseta, para que nombrase inquisidor a fray Gaspar Jutglar a fin de que éste delegara sus funciones en el reino de Valencia en Juan de Orts y Cristóbal de Gualbes. Entonces el rey extendió un nombramiento en favor de estos dos últimos e incluyó la bula del 1 de noviembre de 1478 para establecer el precedente de que también en Valencia tenía derecho a escoger inquisidores. Si el precedente era aceptado, el mismo procedimiento podía aplicarse a los demás reinos.

La maniobra fracasó porque en el invierno de 1481 llegaron a Roma dos reclamaciones paralelas e igualmente eficaces. El dominico fray Francisco Vidal denunciaba el abuso que se había producido y el fraude que para la Orden significaba el nombramiento de Orts y Gualbes. Casseta reaccionó destituyendo a Jutglar con lo que privaba de autoridad sus decisiones. La otra fue presentada por algunos conversos sevillanos, Juan de Sevilla y su mujer Leonor Fernández, Diego y Elvira de Montoya, Francisco Fernández de Sevilla, que denunciaban tres faltas: los nuevos inquisidores no cumplían las prescripciones del derecho canónico, actuaban con 
Cohesión e ideal sociales en la España de los RR.CC.

rigor excesivo y quebrantaban la jurisdicción ordinaria de los 0bispos. Aunque Sixto IV se dio cuenta del error cometido al otorgar a los Reyes Católicos aquellos poderes, era muy tarde para rectificar de manera absoluta. Tomó en muy breve tiempo, dos decisiones importantes. El 29 de enero de 1482 un breve aclaraba el sentido de la bula del 1 de noviembre de 1478, haciendo la cautelosa y tímida advertencia de que si no se destituía a Morillo y San Martín era «para que no pareciese que reprobábamos a éstos como menos idóneos, inhábiles e insuficientes y, por tanto, condenábamos el nombramiento hecho por vos», y señalando que los efectos de aquella bula no podían extenderse a la Corona de Aragón. Los Reyes Católicos sostuvieron a sus inquisidores y el Papa, que necesitaba de los reinos españoles, no se atrevió por ahora a ir más lejos. Sin embargo -aquí se ve la larga mano de la Orden- el 11 de febrero Sixto nombraba ocho nuevos inquisidores para la Corona de Aragón, los cuales habían sido seleccionados directamente por Casseta. En la lista aparece por vez primera el nombre de fray Tomás de Torquemada ocupando el séptimo lugar. Por último, la bula del 18 de abril de 1482 establecía normas de justicia: se prohibía a inquisidores proceder separadamente, se ordenaba mostrar a los reos el proceso, con nombres y declaraciones de testigos, y no mantener secreto como venían haciendo, se autorizaban las apelaciones a Roma y se otorgaba a obispos y vicarios la facultad de absolver a los conversos que, confesando sus culpas, solicitasen la debida penitencia. Si el Papa se hubiera mantenido firme en este propósito, muchos de los daños que vinieron después se habrían evitado. Pero la política italiana era muy compleja y la posición del Papa y de sus nepotes demasiado difícil.

Torquemada, subprior de Santa Cruz de Segovia era un personaje importante en Roma, sobrino del famoso cardenal de este nombre que tanto papel jugara en las negociaciones con los husitas. Debemos retener el dato de que figura en el proyecto de la Orden de Predicadores para retomar las riendas del derecho inquisitorial. Por desgracia desconocemos muchos de los detalles de una negociación que dura desde febrero de 1482 hasta octubre de 1483 y tenemos que recurrir a hipótesis y supuestos. Estamos en los primeros meses de la guerra de Granada y, también, en uno de momentos de crisis en Italia. Fernando y Sixto se necesitaban recíprocamente, y por eso acercaron sus posiciones. El acuerdo parece haberse logrado mediante estas tres concesiones:

- Sixto IV, a propuesta de Isabel, designó a un obispo, Iñigo Manrique, como juez de apelaciones contra la Inquisición de modo que éstas pudieran ventilarse en la Península sin excluir en absoluto la apelación de Roma en ciertos casos (25 de mayo de 1483). 
- Se prohibió a fray Cristóbal de Gualbes ejercer como inquisidor anulándose su nombramiento aunque, ante la cólera del monarca, se hizo la salvedad de reconocer que había sido correcto en sus actuaciones.

- El 17 de octubre de 1483, en virtud de un breve, Sixto IV nombró a Torquemada inquisidor general en la Corona de Aragón con facultad para designar otros jueces subalternos. En este caso no se invocaba la bula del 1 de noviembre de 1478 que carecía de vigencia.

Aunque Fernando comenzó rechazando el nombramiento de Torquemada, porque venía envuelto en injurias contra Gualbes que revertían sobre él, que le había nombrado, acabó aceptando después de prolijas negociaciones que duraron meses. Pero los datos documentales, como don Antonio de la Torre y el P. Llorca ya indicaran, obligan a afirmar algunos puntos clave. Fray Tomás comenzó sus funciones siendo inquisidor general en la Corona de Aragón y como tal fue aceptado por los Reyes Católicos el 23 de julio de 1484. Su nombramiento revestía una gran importancia porque parecía como si la Orden retomase las riendas que perdiera en 1478. El inquisidor general era nombrado por el Papa y, a su vez, designaba los otros jueces: a él eran dadas facultades para conocer todas las causas, dictar normas para el funcionamiento de los tribunales y en definitiva unificar la Inquisición.

En una fecha que hay que situar antes del 29 de noviembre de 1484 Torquemada fue nombrado también inquisiclor general en Castilla.

Fue confirmado por Inocencio VIII el 3 de febrero de 1485. Sin duda los reyes aceptaron, puesto que le prestaron su apoyo. Entre inquisidores por él nombrados figura curiosamente fray Gaspar Jutglar. Se producía con fray Tomás la unidad institucional que perseguían los Reyes Católicos. Queda la sospecha de que algunos de los breves a que hemos aludido fuesen fórmulas pactadas entre Fernando y el Papa. Que a la larga la Corte de Roma cedió en toda la línea, resulta indudable puesto que en 1488 -Torquemada iba a prolongar su mandato todavía diez años- Inocencio VIII concedió a los reyes facultades para nombrar un nuevo inquisidor general cuando se produjera la vacante.

\section{La Inquisición fuerza la prohibición del judaismo}

De este modo, en un proceso relativamente largo, se había creado un aparato represivo al servicio de la Corona en un ámbito concreto: el de los 


\section{Cohesión e ideal sociales en la España de los RR.CC.}

delitos contra la fe. Aparecieron tribunales en muchos lugares del reino. Siendo Torquemada castellano, los conversos de Zaragoza y de Valencia que contaban con fuertes influencias, lograron que la cuestión se planteara en términos de contrafuero, es decir, algo contrario a las libertades del reino. No se planteaba así la cuestión de fondo - si el delito de herejía debe ser castigado- sino el de forma, esto es, si el nombramiento de jueces correspondía al reino o al rey. Fernando se encolerizó sosteniendo lo segundo, y llegó a amenazar a la diputación de Aragón con serias represalias. El asesinato del inquisidor Pedro de Arbués en la catedral de Zaragoza (14/15 septiembre 1485) favorecería los propósitos del monarca que tendía a demostrar que los conversos eran gente peligrosa.

Tocamos así una de las consecuencias principales de la doctrina del «máximo religioso»: ningún delito era comparable a aquel que atentaba a la fe. De este modo, aunque los inquisidores carecían de determinadas facultades como la censura de libros o las decisiones en asuntos políticos, su influencia social desbordó los límites establecidos alcanzando mucha extensión: cuestiones que hoy consideramos propias del derecho común entraban en los aspectos religiosos. El Santo Tribunal funcionaba como una parte de las instituciones del Estado -había una sección del Consejo para él- pero en términos generales puede decirse que se hallaba por encima del mismo.

Así sucede, por ejemplo, en el caso de los judíos. No tenemos noticia de que en las conversaciones con Nicolás Franco se haya pensado en medidas contra ellos. Hasta 1482 por lo menos, se procede a restablecer, ordenar y hacer más eficaces las leyes en que las aljamas veían una eficaz protección. Las Cortes tomaron acuerdos, en relación con la usura y el aislamiento de sus barrios que reputamos como desfavorables pero de las que los judíos también veían lados ventajosos. Muchos judíos actuaban en la corte. En 1484 un viajero polaco, Nicolás Poplau, oyó decir que la reina Isabel era favorable a ellos y, todavía en 1487 las aljamas castellanas comunicaban a la comunidad judía de Roma que era para ellas verdadera fortuna contar con reyes tan justos y con un rabino mayor tan eficiente como Abraham Seneor.

Sin embargo, esto no impedía que, dentro de la mentalidad del tiempo la práctica de la religión judía fuese considerada como algo malo que debía ser «tolerado e sofrido» por otras razones como la esperanza de que se convirtiesen o las aportaciones económicas que de algún modo hacían a la comunidad. La relación entre cristianos y judíos era indeseable. Esta doctrina no era específicamente española: desde que en 1248 un tribunal 
universitario en París condenara a la hoguera al Talmud, como libro herético y blasfemo, la Cristiandad entera compartía la idea de que la doctrina talmúdica era de inspiración satánica y se proponía impedir a los judíos que comprendiesen que la Promesa se había cumplido ya en Cristo. Si una doctrina es de tal modo perniciosa, lo mejor es suprimirla. De hecho en Inglaterra, Francia, Nápoles y otros muchos países europeos se había prohibido la estancia de los judíos y en una fecha tan lejana como 1313, obispos reunidos en el Sínodo de Zamora habían reprochado a los monarcas castellanos que protegieran a los judíos. En 1391 se había desatado una terrible persecución popular, con millares de asesinatos y un número crecido de conversiones forzosas. No podía pedirse a los descendientes de quienes así se bautizaran, que no sintiesen la nostalgia de su religión. Pero el retorno al judaismo estaba radicalmente prohibido.

La Inquisición fue establecida para limpiar a la sociedad cristiana de aquellos que pretendían «judaizar». Los predicadores exageraron los males de esta tendencia y consiguieron crear una atmósfera de temor, recelo y odio. Pero los inquisidores se encontraron pronto en una situación incómoda: no tenían autoridad sobre los judíos de modo que se les pedía que extirpasen una enfermedad mientras que los focos de la misma permanecían intactos. Todo el mundo parece haberles acompañado en esta aversión a los judíos. Las disposiciones para asegurar el aislamiento de las juderías se cumplieron con abusos, en algunos casos incalificables. Es un error muy burdo el de quienes tratan de decir que la expulsión fue algo impuesto desde arriba. Los reyes cedieron a las presiones que de todas partes se hacían y trataron de moderar los efectos consintiendo a los judíos la posesión de todos sus bienes y activando las conversiones. Pero, por lo demás, compartían el pensamiento general: el judaísmo era un mal que debía desaparecer.

La iniciativa partió de los inquisidores. Ya en 1483, como hemos indicado, se prohibió la estancia de judíos en las diócesis de Sevilla, Cádiz y Córdoba. Luego Torquemada insistió hasta conseguir que la prohibición se extendiera a todo el reino. Es muy posible que, teniendo en cuenta los perjuicios que iba a provocar, se haya demorado la decisión hasta el fin de la guerra de Granada. La expulsión significaba una pérdida bastante considerable para las rentas del patrimonio real.

El decreto que Torquemada redactó y los reyes firmaron y sellaron, nos ayuda a comprender uno de los aspectos negativos del «máximo religioso». Aunque ordinariamente nos referimos al episodio como «expulsión de los judíos» sería más exacto decir que se trataba de prohibir la resi- 
dencia, transcurrido un plazo de tres meses a quienes siguiesen practicando aquella religión. No se podía obligar a nadie a bautizarse, pero quienes lo hicieron fueron integrados en la sociedad cristiana con nombres y apellidos que velasen su antigua condición. Así, por ejemplo, Abraham Seneor pasó a llamarse Fernando Fernández Coronel. Al ser extranjeros domiciliados conservaron la propiedad de todos sus bienes debiendo sujetarse a las leyes del reino en cuanto a la salida de dinero. Se ofrecieron ventajas fiscales y exención ante los inquisidores. Aquellos que, después de haber salido, regresaban para ser cristianos, tenían derecho a recobrar sus inmuebles pagando exactamente el precio que por ellos hubieran recibido. Curiosa mentalidad la de Andrés Bernáldez, cura de Los Palacios: se le partía el alma viéndolos víctimas de tantas calamidades, pero culpaba a los propios judíos y a su terquedad que no querían reconocer a Jesucristo.

\section{La expulsión de los musulmanes}

Los autores más recientes han dado mucho relieve a la expulsión de los judíos, pero olvidan a veces que la misma medida, por otro conducto, fue aplicada a los musulmanes. En este asunto concreto se produjeron diferencias de opinión entre Fernando e Isabel o, quizá, entre los consejeros de uno y otro. La prohibición del Islam sería rigurosa en Castilla pero no en Aragón y Valencia donde los moriscos pudieron continuar hasta principios del siglo XVII. La conquista del reino de Granada, obra que Femando contemplaba con una especie de orgullo personal, se había conseguido en un plazo relativamente breve, de nueve años, merced a las capitulaciones que se fueron ofreciendo, las cuales autorizaban a la población musulmana a seguir en la práctica de su religión. Esas capitulaciones no se oponían, según los reyes, a una intensa labor de proselitismo a la que se entregó con ahínco fray Hernando de Talavera. Los métodos del famoso jerónimo eran siempre moderados: convencer con razonamientos, atraer con buen trato. Los alfaquíes comenzaron a mostrarse inquietos: cualquier comunidad religiosa sometida cuando empieza a experimentar presiones y halagos, desde arriba, ve perder poco a poco, sus adeptos. Por otra parte, las conversiones al Islam estaban prohibidas. Por tanto, los dirigentes de la comunidad musulmana comenzaron a comprender que el proselitismo conducía lentamente a la reducción. Las conversiones eran más frecuentes en los medios urbanos y en los sectores acomodados.

En 1499 los Reyes hicieron una visita a Granada, que seguía siendo una ciudad mora. Cisneros iba con ellos y atizó sus temores: el proseli- 
tismo iba demasiado lento. Convenció a Isabel para que se le concedieran poderes para multiplicar las conversiones. No cabe duda de que algunos de sus procedimientos rayaban la crueldad. De este modo se colmó la medida y se produjo el gran levantamiento de 1500. La guerra fue dura. Para aplastar la rebelión se llevaron fuertes contingentes de tropas; corrió mucha sangre. Fernando llegó a encolerizarse con el cardenal, pero admitió el argumento establecido por el Consejo Real: al tomar las armas, los «moros» habían quebrantado las capitulaciones de modo que la condición de respetarles en su religión ya no existía; en consecuencia, en los nuevos pactos de rendición debían dárseles únicamente dos opciones, la de bautizarse o emigrar. En definitiva, se había llegado a la misma opción de 1492 con los judíos, sólo que en este caso se tomaron precauciones para que fuesen muchos los convertidos y pocos emigrados. El 11 de febrero de 1502 una Pragmática extendía a todo el reino de Castilla la prohibición de que habitaran en ella musulmanes. Los mudéjares de Aragón y Valencia no fueron afectados por esta decisión.

\section{Los rasgos de una reforma}

Conducir a la comunidad política a una unidad en la fe era fundamento para la doctrina del «máximo» pero no su verdadera meta: a éste se orientaban otras disposiciones que pretendían elevar el nivel religioso, especialmente en aquellos dos aspectos que apuntaban a lograr cambios en la vida religiosa y una mayor preparación intelectual.

No bastaba con defender a la Cristiandad de sus enemigos de dentro y de fuera; era imprescindible que esa Cristiandad creciera en calidad dando nuevos frutos. Fernando e Isabel, que recibieron de un modo oficial el título de «Católicos» otorgado por el Papa, aceptaron los principios de la reforma iniciada en Castilla en el último cuarto del siglo XIV y que incorporaba poderosas influencias de la «observancia» italiana y de la «devotio moderna» de Renania. Se entendía por reforma una empresa ambivalente de restablecimiento de disciplina en el clero regular y secular y al mismo tiempo, de tendencia a la oración y meditación, caminos de vida interior que conducen a la ascética y la mística.

Habían iniciado la marcha los jerónimos españoles con una fundación realizada en Lupiana (Guadalajara) por Fernando Yáñez y Pedro Fernández Pecha, que estuvieron sometidos a influencia indirecta aunque muy poderosa de Santa Catalina de Siena; de ella partiría esa noción sustancial a la reforma española y tan contraria al nominalismo, de que 
los seres humanos pueden alcanzar, por ascensión contemplativa, un grado de vida espiritual que consiste en vaciarse de si mismos para llenarse de Dios. Si pensamos que jerónimos han sido además de Lupiana, La Sisla, Guadalupe, El Prado de Valladolid, Yuste y El Escorial, comprenderemos muy bien la importancia de un fenómeno que, entre otros importantes detalles, rechazaba esas distinciones entre cristianos viejos y nuevos. Tal vez por esto Fernando, al regresar a España en 1507, tuvo que defender a fray Hernando de Talavera de los desmanes de un insensato inquisidor. Tampoco puede fiarse al azar el hecho de que algunas de las principales decisiones del reinado se tomaran en Guadalupe, donde Isabel disponía de una celda a la que llamaba «mi paraíso».

A este vasto movimiento, que tenía por objeto colocar modelos de perfección en la vida cristiana haciéndoles servir de guía para toda la sociedad, se sumaron franciscanos y dominicos «de la observancia», benedictinos reformados de la congregación de Valladolid y cartujos que, desde Scala Dei, en Valencia, se extendieron a los demás reinos. En la política de los reyes se otorgaba a monjes y frailes un papel decisivo: orientadores de la religiosidad, eran, por medio de la oración intermediarios entre Dios y los hombres y, por el ejemplo, modelos de vida. Femando apoyó todo esto tratando de extenderlo a otros ámbitos como el de las Ordenes Militares en que tuvo escaso éxito.

Con paciencia infinita y no pocos dispendios, pudo rescatar Monserrat, patrimonio para un famoso nepote, Giulio della Rovere, que sería Papa, y prácticamente arruinado. A fin de proceder a su restauración, envió allá al prior de Valladolid, fray García Jiménez de Cisneros, que no tiene parentesco conocido con el famoso cardenal, y a unos cuantos monjes. El benedictino era un hombre «moderno»: una de sus primeras decisiones consistió en instalar en el monasterio una imprenta, porque la juzgaba vehículo adecuado para la difusión de doctrina y de modelos de piedad. Llevaba consigo el manuscrito de una obra preciosa que tituló Exercitatorio de la vida espiritual. De acuerdo con sus enseñanzas, íntimamente conectadas a las corrientes del Humanismo, la virtud de la religión debe ser «ejercitada» como las demás para que dé su fruto. Es ella la que permite al alma contemplativa elevarse a Dios. La propuesta, por tanto, era de una vida espiritual lograda mediante ejercicio. A Montserrat llegaría, en profunda conversión, San Ignacio de Loyola que es el autor de los Ejercicios espirituales.

En el ámbito de esta religiosidad, la obra fomentada y a veces directamente realizada por los Reyes Católicos, tuvo consecuencias durade- 
ras. La reforma española quedó enmarcada en el optimismo filosófico y teológico que caracteriza a Santo Tomás de Aquino: la criatura humana posee capacidad para trascenderse y, dotada de libre albedrío, se encuentra en condiciones de progresar y mejorar en línea de conocimiento especulativo y de conducta moral. Hubo resistencia en algunos religiosos a quienes lógicamente molestaba cambiar un modo cómodo de vida, pero los reyes comprobaron que, en las Cortes, había una opinión extremadamente favorable a su tendencia y modo de pensar.

Sin la presencia de Isabel y Fernando en el trono, los reformadores no habrían podido contar seguramente con el respaldo económico y diplomático que necesitaban. La abundante documentación publicada por don Antonio de la Torre revela que la vía diplomática fue preferentemente aragonesa, pero la económica castellana. Según el P. García Oro las líneas de actuación de los reyes pueden enmarcarse en tres sectores distintos: selección de personas, obtención de bulas y breves pontificios, establecimiento de fuentes de riqueza. Consecuencia inevitable de esta colaboración fue una interdependencia entre Iglesia y Monarquía, algo que eclesiásticos de nuestros días censuran y aborrecen. Pero interdependencia no significó en modo absoluto sometimiento; exageran los que creen que la Iglesia quedó sometida al Estado o que la Monarquía española fue una especie de teocracia. Algunas veces tuvieron los reyes motivos para quejarse porque las concesiones otorgadas les llevaban más lejos de lo previsto. En otras oportunidades las quejas procedían de la Iglesia. Las relaciones entre ambas potestades se mantuvieron dentro de límites que una y otra juzgaban aceptables, lo que no excluía algunos enfrentamientos.

\section{Patronato}

La clave de cualquier entendimiento se encontraba en la colación de grandes beneficios, como abadías y obispados. Desde 1421 la que el Concilio de Constanza reconociera como «nación española», esto es, los reinos peninsulares, se veía afectada por la bula de Martín V que reservaba al Papa el nombramiento de todos los obispos y beneficiarios. Esto significaba que el Pontífice escogía libremente los candidatos cuando la vacante se producía «in Curia», es decir por fallecimiento de alguien que residía en la Corte de Roma, lo que daba lugar a abusos pues se interpretaba a veces como aplicable a alguien que estuviera de visita en la Curia. En todos demás casos el rey tenía derecho a proponer a los cabildos un candi- 
dato y "presentarlo» después para su nombramiento. Isabel intentó convencer al Papa de que el sistema podía funcionar bien porque la selección de personas se haría cuidadosamente; cumplió su palabra y las nuevas generaciones de obispos abundaron en personalidades sobresalientes. Fernando compartía este criterio, aunque su manga era más ancha: estaba dispuesto a aceptar, por razones políticas, candidatos romanos nada convenientes y no desdeñaba la oportunidad, como en el caso de Zaragoza en 1478, de introducir a un bastardo suyo de nueve años de edad en una diócesis de tanta importancia. El muchacho, luego, respondió bastante bien pero eso no hace al caso.

Los reyes aspiraban a reforzar el sistema pasando del simple derecho de «presentación» a un «patronato» que les permitiera simplemente designar a nuevos titulares. De este modo se evitaban las ingerencias que de cuando en cuando se producían por parte de Roma. Tras años de negociaciones, en que Fernando puso más interés que su esposa, se llegó en 1486 a una fórmula que los monarcas consideraron satisfactoria: en todos los antiguos reinos se mantenía el régimen de "presentación" pero en los recientemente adquiridos, como eran Granada y Canarias -es el precedente que se aplica en América- en donde a los reyes correspondía asumir todos los gastos de creación y sostenimiento de las nuevas sedes, se establecía el "patronato». Este régimen no se limitaba a los obispados sino que se hacía extensivo a otros beneficios.

Los defectos contenidos en el procedimiento no se advirtieron porque las designaciones fueron recayendo, en general, en personas idóneas. Se podía establecer la comparación con los resultados de aquel desenfrenado nepotismo que imperaba en Roma. Isabel podía afirmar que al impedir que César Borja fuera arzobispo de Sevilla, estaba prestando servicio a la Iglesia. Por otra parte, no hay que olvidar que los obispos prestaban servicios correspondientes a altos funcionarios de la Monarquía, en especial en campos jurídicos o diplomáticos, y hubiera resultado un contrasentido que fueran contrarios a ella. Sus opiniones eran especialmente tenidas en cuenta en las cuestiones que de alguna manera afectaban a la moral o a la justicia.

\section{La reforma de los Estudios Generales}

El aspecto más importante de esta política de unidad en la fe para el desarrollo de la sociedad aparece reflejado en las universidades y en todos los aspectos de la cultura. El siglo XV registra un verdadero entu- 
siasmo por el saber y en muchas ciudades, núcleos que darían origen a nuevos Estudios Generales. Los Reyes Católicos mostraron honda preocupación por el tema; deseaban una reforma que les devolviese toda la potencia inicial pero se mostraban poco inclinados a las novedades. En cierta ocasión la reina Isabel asistió a una colación del grado de doctor en San Andrés de Valladolid, abonando los gastos, para demostrar el interés que la Universidad le ofrecía. No tenemos noticia de que haya visitado Colegios Mayores, aunque es más que probable. Algunos de estos, como el de San Esteban de Salamanca, eran, a veces, fuente de conflictos. Su política universitaria, que sirve de precedente a la que se emplea en América, puede definirse como unificadora. En las Cortes de Toledo de 1480 dispusieron que todos títulos, antes de que pudieran ser utilizados para ejercicio profesional, tendrían que ser revalidados ante un tribunal de maestros designado por el Consejo Real. Y solicitaron del Papa que confirmase esta disposición que afectaba a graduados en el extranjero.

Aunque Salamanca, Valladolid y Lérida conservaron su rango de universidades mayores, otorgando grados máximos en Teología, Derecho o Medicina, comenzaban ya a establecerse cátedras y colegios en Santiago, Sigüenza, Valencia, Barcelona, Mallorca, Zaragoza y Sevilla, destinadas a evolucionar hasta convertirse en nuevos Estudios Generales. Los monarcas mostraron decisión de que ciertos sectores de la administración o de la justicia quedaran reservados a titulados universitarios y que la práctica de la Medicina no pudiera realizarse sino por aquellos que acreditasen la preparación necesaria ante el tribunal del «protomédico» que era a su vez, catedrático en Valladolid. En 1493 se promulgó la Pragmática prohibiendo ser relator, pesquisidor o alcalde de la justicia sin haber cumplido al menos un decenio de estudios universitarios.

Pero no podía cerrar los ojos ante los desarreglos e indisciplina que dominaban en las aulas, especialmente por tres causas: el absentismo - una vez obtenido el título de catedrático, que proporcionaba gran dignidad, se abandonaba la enseñanza para obtener puestos mejor remunerados-, las irregularidades, a veces violentas, en las oposiciones para provisión de cátedras, y los desórdenes de los estudiantes. El 14 de marzo de 1481 se llegó en Valladolid al extremo de que un opositor derrotado en la cátedra de Decretos, doctor de Villalón, fuera a tomar posesión de la misma acompañado de una banda de hombres armados.

Ante esta situación, ¿qué hacer? Los consejeros eclesiásticos de los reyes, el cardenal Mendoza o fray Alonso de Burgos, entendieron que la solución estaba en colegios, algunos de los cuales venían funcionando en 


\section{Cohesión e ideal sociales en la España de los RR.CC.}

Salamanca según el modelo que instaurara en Bolonia el cardenal don Gil de Albornoz. En estrecho paralelismo, fray Alonso fundó San Gregorio y el cardenal Mendoza Santa Cruz, ambos en Valladolid. Este último, recogiendo todas las experiencias ya vividas, se proponía ser un modelo para que se establecieron en el futuro y, de hecho, durante más de un siglo, constituyó la institución paradigmática, destinada a preparar minorías reducidas y selectas, ejemplo para los colegios que vinieron después en Santo Domingo, en Lima o en Méjico. En Santa Cruz vivían al principio tan solo trece colegiales. Más adelante èl número se amplió al aceptarse condiciones de huéspedes o de adheridos.

Descendamos a algunos detalles. Santa Cruz, cuya bula pontificia de fundación data del 29 de mayo de 1479, se estableció en 1483, después de largas y delicadas negociaciones con el municipio -abastecimientos, circulación, derechos de mercado-, con el Estudio General -docencia- y con la propia Universidad de los maestros y escolares para el ejercicio de jurisdicción y la colación de grados. El Estudio y el Colegio ocupaban edificios muy próximos. De este modo logró Mendoza una plena legitimación que pudo posteriormente plasmar en el «Cuadro de estatutos y composición». La rigurosa selección de aspirantes y la generosa Biblioteca que aun hoy sorprende por la riqueza de obras científicas, garantizaba el alto grado de preparación.

Seis grandes colegios juntaban ahora Valladolid y Salamanca, aparte de otros que estaban naciendo; con ellos se lograba disponer de una minoría exquisitamente preparada de acuerdo con el ideal de los humanistas. La traza arquitectónica de los nuevos edificios revelaba ya la influencia italiana. Pero a Fernando e Isabel la fórmula de colegiales no bastaba; consideraban imprescindible reformar los Estudios Generales a de que cumplieran su función. La educación, en todos los niveles, era una fuerte preocupación de su política.

De todo esto hablaron con Cisneros que tenía experiencia directa, ya que durante seis años había estudiado en Salamanca, Universidad de la que salió con el título de bachiller en Decretos. Los reyes, a quienes el Estudio dedicaría el medallón que aun campea en su fachada, querían que Salamanca, primera siempre de las Universidades, recobrara todo su vigor y disciplina. Cisneros disentiría muy pronto: mejor que aplicar arreglos, en todo caso insuficientes, sería dedicarse a constituir una Universidad sobre moldes nuevos. Y ponía el ejemplo de San Esteban, tan importante para el futuro. San Esteban era el núcleo esencial del saber dominicano. Pero había surgido entre los frailes predicadores un movi- 
miento de opinión, manifestado ya en el capítulo de 1447, que juzgaba incompatible la estricta «observancia» con el grado de disipación en la disciplina que exigían los estudios. Cisneros era «observante» y muy riguroso pero no pensaba de esta manera. Tal vez hubiera cierta incompatibilidad entre la Universidad actual y la vida franciscana rigurosa, pero tendría que desaparecer si se establecía otro modelo de Universidad. Otros frailes pensaban como él.

En 1475 fray Alfonso de San Cebrián, vicario general de los observantes dominicos, contando con el apoyo de los reyes y de la Sede romana, pretendió sumar San Esteban a la observancia. Los frailes allí residentes se opusieron alegando lo mismo que se dijera en 1447: la vida del estudio reclama cierta libertad en las normas y por eso resulta incompatible con las rigurosas normas que regulaban la existencia de reformados. A pesar de su resistencia la incorporación fue impuesta en 1488 con resultados bien negativos. De esto informaba Cisneros a los reyes: de nombre eran observantes, en la práctica las cosas seguían como antes; y trazaba un cuadro muy pesimista acerca de la poco edificante vida universitaria. No, era mucho mejor lo que se estaba haciendo en Sevilla al establecer un Estudio General, para observantes, sólo para ellos, y para quienes los observantes decidiesen admitir. Aquí estaba la inversión de los términos. En vez de colegios dentro de un Estudio, un Estudio al servicio de los colegios.

Los reyes insistieron: querían mucho a su Salamanca. En 1501 el corregidor hizo llegar al Consejo Real un in forme muy pesimista acerca de la vida universitaria. Los estudiantes, al formar parte de una corporación privilegiada -que es lo que significa propiamente «universidad»-gozaban de libertades que no tenían los ciudadanos y llevaban una vida desarreglada. Para incrementar sus ingresos ejercían oficios que no siempre eran honestos y para evitar que sus mancebas y mozas del partido fuesen detenidas las alojaban en iglesias y monasterios. Cisneros aceptó formar parte de la comisión que con fray Diego de Deza y Alfonso Carrillo, iba a realizar una rigurosa visita de inspección: algunas medidas fueron tomadas; probablemente la más eficaz de todas fortalecer la vida colegial de San Esteban. Pero esta visita sirvió para fortalecer en el cardenal una idea que venía acariciando desde hace mucho tiempo atrás, la de fundar un Estudio que ese verdaderamente «nuevo» en su estructura y en su organización. Indicó Alcalá de Henares, una ciudad de su diócesis.

Había un precedente. El arzobispo Carrillo había dedicado algunas rentas al sostenimiento de tres cátedras en dicha ciudad. La idea de Cis- 
neros iba ahora mucho más lejos: fundar un Colegio bajo la advocación de San Ildefonso y proporcionarle las funciones de impartir las enseñanzas y conceder grados. La nueva Universidad de Alcalá sería, pues, una suma de colegios. Ya en las bulas que en previsión del proyecto consiguiera de Alejandro VI en 1499 y 1500 se le daba autorización para fundar nuevas cátedras en Teología y Derecho.

En esto consistía la originalidad: se trataba de introducir tres líneas diferentes de acción. Se sumaba la resistencia disciplinar de los colegios al elevado magisterio de un Estudio General. Los conflictos entre observantes y claustrales o entre manteístas y colegiales que tanto dificultaban la vida de Salamanca, no debían tener lugar en Alcalá. Pero en este elevado magisterio la dedicación científica y la apertura a nuevos métodos de investigación abrían paso a un espíritu muy distinto del de la Escolástica. Cisneros invitó a Desiderio Erasmo a sumarse al claustro de la nueva Universidad, pero el sabio de Rotterdam respondió que no podría acostumbrarse al clima seco de la meseta castellana. Promovió también esa edición de la Biblia que proporcionase a todos cristianos los textos originales de las distintas lenguas. Esa es la Políglota complutense. Por último, buscó una ciudad que pudiera ser dominada, de manera absoluta, por quienes llegaban a ella buscando el estudio y una forma de vida.

La Monarquía precisaba de esta formación de minorías de letrados, para el servicio de la que no dudamos en considerar primera forma del Estado Moderno. En la base estaba la comunidad llamada Reino, compuesta de bautizados; en la cúspide la soberanía que Dios otorga al rey cuando, en la cuna, le impone el deber de reinar. De esa soberanía, el monarca era solo depositario y en su deber entraba el cumplimiento de la ley divina positiva, de las leyes humanas consuetudinarias y de los privilegios y fueros que forman las libertades del Reino. La propia comunidad política por su esencialidad cristiana, obligaba al rey a someterse a las dimensiones morales de la fe. Era intolerante con quienes no compartían sus creencias, pero sometía todas las actuaciones públicas a esa ley natural que Dios ha impreso en el alma de cada hombre. Es lo que los maestros de Salamanca comenzaban a llamar derecho de gentes o derechos humanos naturales.

\section{El ideal caballeresco y nobiliario}

Desde 1481 se declaró, por ley, que si alguna reliquia de servidumbre aun quedaba en cualquier lugar de los reinos, debía considerarse extingui- 
da. En 1486, cuando la sentencia de Guadalupe estableció las indemnizaciones que los payeses de remensa tenían que abonar a los señores de la tierra para quedarse con ella al ingresar en el status de libertad, fue la libertad personal norma jurídica para todos los habitantes cristianos del reino. Había algunos esclavos, insertos en servicio doméstico, pero se trataba de mercancía comprada fuera, ya en condición de esclavitud, porque, de acuerdo con las leyes de la Iglesia, la esclavización estaba prohibida.

Había, pues, una igualdad de base: todos los súbditos eran cristianos, libres y capaces de alcanzar la salvación de su alma. Lo que no excluía la posibilidad de establecer diferencias. Es característico de la época que se reconociesen dos clases de diferenciación social: la que procedía de la función y la que dimanaba del dinero; la primera era esencial; la segunda coyuntural y accesoria. Por encima de una masa general de campesinos, algunos de los cuales eran propietarios ricos, y hasta muy ricos, y otros pobres, que constituían más del $80 \%$ de la población (los villanos) se alzaban tres estamentos privilegiados, con derechos y obligaciones que les eran propios: los eclesiásticos, los nobles y los ciudadanos.

Lo que importa destacar en una sociedad estamental es que la comunidad política o social se halla representada por una minoría privilegiada: eclesiástico es el que reza y estudia, noble el que combate y gobierna, ciudadano el que comercia y manufactura. Y estas funciones son tan rígidas que un noble dedicado al comercio o a «oficios mecánicos» perdería su condición. Desde finales del siglo XIV la sociedad española había experimentado profundas transformaciones que, de manera diversa pero con la misma intensidad, habían afectado a los tres estamentos. Los historiadores se refieren a ellas como a una «revolución Trastámara». Toda ella está impregnada de mentalidad aristocrática. También de Humanismo: sin tener en cuenta los principios de los humanistas es casi imposible entender su mentalidad social.

Se había dado un gran margen de confianza a la capacidad del hombre -su racionalidad y su libre albedrío- para la autorrealización. En el aspecto religioso la reforma típicamente española propendía más a «vivir» el sristianismo acudiendo a la oración contemplativa, que a cambiar las estructuras eclesiales. Dicha reforma comenzó a finales del siglo XIV con la creación de los jerónimos, la implantación de los cartujos y la aparición de una nueva familia benedictina presidida por Valladolid: desde aquí se extendió a las otras Ordenes y también al clero secular.

Relacionándose con los postulados que Santa Catalina de Siena estableciera, la reforma española introdujo en la mentalidad de los eclesiás- 
ticos algunos principios básicos orientados hacia la actividad. La condición cristiana no era pasiva ni se limitaba a recibir enseñanzas e instrucciones: recordémoslo, que hacia 1492 Fray García Giménez de Cisneros, prior de San Benito de Valladolid y luego abad restaurador de Monserrat, había sintetizado estas ideas en un libro que llamó Exercitatorio; aunque no cabe duda de que existe algún paralelismo entre este y las corrientes renanas de la «devotio moderna», hay también aspectos originales que serán desarrollados por San Ignacio de Loyola como acabamos de ver. Clero y religiosos se sentían llamados a una ampliación de su influencia, hacia Africa, donde imaginaban amplios campos de batalla contra el Islam, y nuevos horizontes donde aún no había sido predicado el Evangelio.

América, surgida inesperadamente, se convertirá luego en campo predilecto: en el siglo XVI lo mejor y no lo peor era enviado allende los mares.

La parte superior del clero se sentía identificada con la nobleza de la que procedían la mayor parte de sus miembros. También en las ciudades la zona más elevada de su sociedad se iguala a la nobleza hasta formar parte de ella: lo que en otras partes es patriciado, aquí se convierte en caballería urbana. Los «ciudadanos honrados» de Barcelona como los «veinticuatro» de Sevilla o de Córdoba, son y se sienten nobleza. En consecuencia, toda la mentalidad social de los sectores no eclesiásticos y aun una parte de estos se vio impregnada de los ideales nobiliarios, que vinieron a coincidir con la de España entera. Tendremos que llegar a la generación de Calderón, que es la de la derrota, para encontrar un cambio.

Un relevo se había producido en la nobleza en la segunda mitad del siglo XIV: los genealogistas tardíos hablan de la sustitución de la «nobleza antigua» por la «nobleza nueva» surgida de las mercedes de los Trastámara. La característica esencial es que las rentas de las que los linajes se sostenían y que eran, al principio, salidas de la explotación directa de la tierra, pasaron a ser ahora rendimientos obtenidos del ejercicio de jurisdicción: justicia, mercados, peajes, etc. Una tercera parte del país, aproximadamente, pasó a ser administrada por linajes de nobles convirtiéndose en «señorío». No era la más rica pero si una plataforma importante. Durante el siglo XV una docena y media de linajes se fue elevando hasta acumular grandes «estados» recibiendo títulos de conde, marqués o duque como señal de este ascenso.

Los Reyes Católicos detuvieron este crecimiento pero consolidaron los linajes convirtiéndolos en colaboradores del Rey. Así se produjo una consolidación social de enorme importancia: España quedó dominada por 
una aristocracia que se distribuía en tres sectores; el de los opulentos que con frecuencia se denominan "grandes»-aunque el estatuto jurídico de grandeza no se producirá hasta la época de Carlos V-el de los simples hidalgos y caballeros que tienen que recurrir a todo su ingenio para poder vivir, y el de los instalados en las ciudades, como son los padres de Melibea en el famoso libro de la Celestina.

Un rasgo común caracteriza a todos estos nobles: el sentimiento de la caballería. En su acepción más simple es el arte de combatir a caballo, pero en el siglo XV había pasado a ser una norma de conducta: las palabras «noble» 0 «caballeroso» se aplicaban y aplican a quienes observaban conducta moral superior o, al menos, estaban obligados a ella. Por contra, «villanía» pasó a convertirse en término injurioso. Esta actitud psicológica es muy reveladora: todo el mundo trataba de imitar a los nobles en su vida y conducta que eran superiores. Los soldados que iban a Flandes tenían que ser tratados como «señores soldados», y los que viajaron a América lo hicieron imbuidos de esa calidad superior.

El cambio social se había producido al mismo tiempo que una gran influencia italiana fortalecía las raíces del Humanismo. El ser humano -enseñaban los humanistas- creado por Dios, ciertamente, contiene en si potencialidades que, susceptibles de desarrollo, le permiten alcanzar un nivel superior de dignidad en sus hechos. El ejercicio de tales potencialidades constituye la virtú, paralela de las virtudes cardinales o sobrenaturales que enseñaba la Iglesia Católica. La meta última a que la virtú tiende desde siempre la «opinión» o «honra» que acompaña a quien la practica y, en definitiva la «fama» que perdura más allá de la muerte. Hay cierta relación entre el premio de la vida eterna que aguarda al que practica las virtudes sobrenaturales y este de la fama, que logran las puramente humanas.

Toda la existencia humana, contemplada desde esta perspectiva, no es sino un tránsito a través del tiempo -tempus fugit recordaban los relojes mecánicos de esta época- que permite alcanzar una vida mejor en el cielo y una buena memoria acá en la tierra. Esta «fama» no es igual para todos sino que depende de las potencialidades específicas que se posean: harán de uno un sabio, de otro un poeta, un político, un guerrero, un navegante, etc. Así como el diamante ha de pulirse para alumbrar la belleza potencial que posee, también el espíritu humano necesita de tal pulimento. Ejercicio y educación pasan a ser aspectos esenciales: una educación que es siempre elitista porque aspira a despertar la virtú. Colocado ante la Muerte, dirá Jorge Manrique que «cumple tener buen tino para andar esta jornada sin errar». 
Cohesión e ideal sociales en la España de los RR.CC.

El Humanismo reforzó otro de los rasgos propios del espíritu de la caballería: «nobleza obliga». No son los derechos y su exigencia los que conforman el comportamiento del noble sino sus deberes y obligaciones. Una mentalidad que resulta difícil de entender cuando consideramos la distancia existente entre los ideales pretendidos y la realidad cotidiana; constantemente encontramos ejemplos de nobles que se portan mal pero esto no debe engañamos: la maldad, también entre nosotros, es noticia mientras que de la bondad no parece necesario hablar. La primera de las virtudes del caballero es, como se dijo en las Cortes de Valladolid de 1385, la lealtad. Hilando fino no debe confundirse ésta con la fidelidad. Un caballero es fiel cuando sigue a su señor sin preguntar por la justicia de su causa, pero es leal cuando evita que su señor pueda cometer iniquidad. Junto a la lealtad hay todo un cortejo -valor, honradez, respeto, conducta exterior- pero no llegan a significar tanto como aquella.

Dos libros deben servirnos de referencia para comprender los efectos de este sentimiento de la caballería sobre el comportamiento social: ambos fueron verdaderos best sellers de la primera mitad del siglo XVI. Se trata del Amadis de Gaula, impreso en 1508, y del Enchiridion militis christiani que en su versión española, Manual del caballero cristiano, apareció en 1529. Entre ambos extremos, las fantásticas aventuras imaginadas para un caballero andante y la profunda reflexión acerca de las virtudes que sirven de plata forma para la conducta de un noble cristiano, iban a moverse varias generaciones de españoles. En definitiva es el Quijote, no sólo la cumbre de la literatura en lengua española, sino el espejo en que se mira, contradictoria, toda la mentalidad social.

Fama y riqueza en cierto modo se contraponen porque no se puede servir a dos señores tan distintos como éstos. También se ayudan. Desde la mentalidad del caballero los bienes materiales y las rentas son un medio, en verdad imprescindible, para conseguir aquella. Lo que resultaría monstruoso sería considerarlos bien en sí mismo, meta de la existencia. Las minuciosas investigaciones que ahora se realizan permiten descubrir las rentas que se obtenían; pero en cuanto a los gastos, ningún registro era concebible. Se gasta lo que se debe aunque después se deba lo que se gasta. La prodigalidad es el vicio del caballero; la avaricia es propia de comerciantes. Muchos señoríos jurisdiccionales arrojaban pérdidas pero nadie se desprendía de ellos porque proporcionaban lo importante, prestigio social. Fortunas adquiridas en otras partes, como la de Quevedo, se invertían en comprar señoríos. ¡Qué pomposamente el famoso literato llegaría a presentarse a sí mismo como el «señor de la Torre de Juan Abad»! 
Estas mismas cualidades y defectos fueron llevados por los españoles a América, en donde arraigaron hasta convertirse en rasgo de su carácter nacional. De un extremo a otro del Continente inmenso la estampa del hombre y el caballo constituye una especie de signo de identidad. Además de cuanto lleva consigo incluyendo cierta grandilocuencia y ampulosidad en los gestos. «Nací contemplando la vida y la muerte» dice una canción popular mejicana. Es como un eco del sentencioso Jorge Manrique: «este mundo bueno fue si bien usásemos de él como debemos».

Otros dos rasgos muy característicos conforman la mentalidad del caballero: el artificio de lo heroico y la nostalgia de una vida más bella. Hace tiempo que Huizinga los descubrió hurgando por la Corte de los duques de Borgoña. No era suficiente poseer valor: éste tenía que ser ofrecido a la contemplación, como si fuese una obra de arte. De ahí la ampulosidad en las maneras, cierto alarde en los momentos difíciles. La entrega de Granada, que es el acontecimiento más importante del año, se ajusta a un ritual. Todos lloran, rítmicamente: los cristianos en la primera misa de la Alhambra y Boabdil con los suyos en el momento de abandonar la hermosa ciudad. Nadie se engañe pues todo estaba pactado y ensayado como en el escenario de un teatro.

La artificiosidad se vincula al caballo, a la espada y, en definitiva al lujo, al alarde y al ceremonial: armadura de plata con espuelas de oro trajo Beltrán de la Cueva al real de Tordesillas en 1475; no eran atuendos adecuados para una ruda batalla aunque sí para la fiesta de la guerra. Gonzalo Fernández cabalga al encuentro del enemigo en Ceriñola mientras dicta una carta anunciando a los Reyes la que será su victoria; y cuando la pólvora salta, dice que son las «luminarias» que se adelantan a festejarla.

Ese artificio que atribuye a la hazaña tanto más valor cuanto más gratuita se presenta, tienen también un objetivo concreto: «cobrar fama». Así lo expresa Pizarro al trazar la raya en la arena de la isla de Cozumel para que la cruzasen los «Trece de la Fama» y, más tarde, Pedro de Valdivia cuando explica al propio Pizarro que no ha venido a América a ganar riquezas sino a ganar fama. Los caballeros e hidalgos que cruzaron el mar no iban, como a veces se cree, en busca de un botín: estaban persiguiendo ante todo su progreso en la escala social. Hernán Cortés se muestra bien dispuesto a enviar el oro y la plata al emperador; a fin de cuentas ha conseguido el salto social prodigioso de convertirse, de golpe, en marqués. Muy poco cuidadoso de sus granjerías se muestra el segundón Gonzalo Fernández; pero sus hazañas le colocan en la cumbre de la nobleza española. 
Nostalgia de un tiempo pasado mejor: esa es otra de las constantes. Hay una íntima contradicción entre los ideales del caballero y la realidad que le corresponde vivir; él la resuelve poniendo la vista en un tiempo pasado que indudablemente fue mejor: "dichosa edad y dichosos siglos aquellos a quienes los antiguos pusieron el hombre de dorados», como dirá en su singular locura don Quijote. Pero también, a veces, esa nostalgia apunta hacia un futuro, un Eldorado que jamás se encontrará. Esa misma nostalgia aparece en ese otro caballero tardío, Martín Fierro, el baquiano argentino, que rememora un tiempo «feliz para la gauchada».

La misma tensión aparece en sus aspectos económicos pues el caballero parece obligado a vivir en la tensión continua que distancia «lo que quiere» de lo que «puede», obligado a disimular carencias, gastando siempre más de lo que tiene. De nuevo Jorge Manrique viene en nuestra ayuda cuando reprocha a su generación esa creencia en que «cualquiera tiempo pasado fue mejor», para acabar él mismo haciéndose la reflexión suprema: «ved de cuan poco valor son las cosas tras que andamos y corremos, que en este mundo traidor, aún primero que muramos, las perdemos». Artificio, nostalgia e insatisfacción son los elementos que espolean a los nobles a buscar un ascenso: las rentas son buscadas no por el disfrute que pueden proporcionar sino porque son el medio infalible para lograr dicho ascenso.

Muchas veces nos hemos preguntado por qué Extremadura dio una proporción tan grande de conquistadores a América. La explicación puede estar en ese punto del ascenso: al consolidarse tres linajes de grandes, en especial los Estúniga, en esa tierra, y afirmarse el dominio de las Ordenes Militares ahora en poder del Rey, no quedaba a los hidalgos y caballeros otra posibilidad de ascenso que saliendo fuera, hacia Italia o hacia América.

Tal fue la mentalidad social que conformó la España de los umbrales del siglo XVI, aquella que inspira inmediatamente a sus literatos. Los sentimientos de la caballería tuvieron escenarios privilegiados para manifestarse; primero fue Granada, guerra caballeresca por antonomasia, luego Italia, más tarde América. Todo aquello que los autores de $L a$ muerte de Arturo, Tirant lo Blanch y Amadís de Gaula describieron -incluyendo el amor humano que hacía penetrar lo femenino en la vida del guerrero, moviéndose siempre en los bordes más afilados de la moral cristiana- fue vivido en una especie de búsqueda de un tiempo y de un espacio donde lo heroico fuese verdaderamente heroico y lo bello satisfactorio. Casi nunca se conseguía la meta: mientras la hazaña estaba en 
marcha irradiaba felicidad sobre sus protagonistas; apenas concluida, sobrevenían el desencanto y las menudas y sórdidas querellas.

Por eso los personajes mejor recordados son los que mueren jóvenes, como Martín de Vargas, el doncel de Sigüenza.

Nobleza y romancero acabaron confluyendo en una afirmación literaria que no puede considerarse literatura épica porque en ella los sentimientos superan a la narración de las hazañas. Del romance se apodera la nostalgia -«que por mayo era por mayo», «Si tu quisieses Granada», «paseábase el rey moro»-lo mismo que el sentido de la fiesta. Pues guerra y fiesta son elementos que se confunden e identifican. La fiesta esencial de caballero era el torneo, remedo de batalla, con peligro para la vida, aunque no demasiado grande, que acostumbra a los nobles a someter el combate a reglas medidas. Luego, estas normas se transfirieron a la guerra, muy escasamente mortífera, librada por combatientes bien entrenados y poco numerosos. La batalla se ordena, precedida de un desafío, y los capitanes descuellan por encima de los soldados gracias a los adornos que componen su cimera.

Se busca, en el adversario la imagen de otro yo, como si estuviera reflejada en un espejo, pues nada honra tanto como vencer a un enemigo grande. La vida del vencido, su honra y su dignidad merecen cuidadoso respeto -aunque haya un fin material interpuesto en el cobro del rescate- y estas condiciones se tributan a los muertos. Si alguien entra en el monasterio de Batalha, en Portugal, que no deje de visitar la tumba del vencedor, el santo condestable Nun Alvares Pereira; verá, junto a ella, otra, que es la del noble castellano Pedro González de Mendoza que, en acto de lealtad, entregó al rey su caballo y murió en su lugar. Lo explican gráficamente las imágenes de los perros interpuestos pues como todo el mundo sabe es el perro signo de fidelidad.

\section{Notas}

1 Basado en varios trabajos: «Mentalidad social en 1492», Torre de los Lujanes (Madrid) 26 (1994); «El máximo religioso» (en Fernando II de Aragón, Zaragoza 1966); «Religiosidad femenina» (Conferencia inaugural al Congreso sobre Beatriz de Silva, León 1993); «Una cuestión dudosa: el nombramiento de Torquemada como inquisidor general» (Homenaje a Vicens Vives, II, Barcelona 1967). 